\title{
¿ES El Procedimiento DE TUTELA DE DERECHOS \\ FUNDAMENTALES UNA ADECUADA HERRAMIENTA \\ DE CONTROL Y SANCIÓN DEL ACOSO LABORAL?: REFLEXIONES A PARTIR DE LA DICTACIÓN DE LA LEY 20.607*
}

\section{JORGE VILLALÓN ESQUIVEL ${ }^{* *}$}

RESUMEN. Hasta la dictación de la ley 20.607, publicada el 8 de agosto de 2012, la ausencia de legislación específica sobre el mobbing o acoso laboral en Chile, ocasionó que gran parte de las respuestas para determinar las soluciones a los conflictos producidos por conductas de acoso laboral, viniera dada por la aplicación práctica que los nuevos juzgados del trabajo han efectuado en relación a la actual normativa contenida en el Código del Trabajo sobre la acción y el procedimiento de tutela laboral. A partir de este somero análisis, surge el siguiente problema: El procedimiento de tutela laboral iconstituye realmente una herramienta adecuada y bastante para controlar y sancionar el acoso moral laboral en nuestro pais? Partiendo de esta premisa, y a través del análisis de fallos dictados por nuestros tribunales laborales, en procedimientos de tutela laboral aplicados al mobbing, el presente trabajo pretende dilucidar si dicha afirmación finalmente se ajusta o no a nuestra realidad actual, como también reflexionar y valorar el reconocimiento del acoso laboral de manera expresa en nuestro Código del Trabajo a partir de la citada modificación legal ${ }^{1}$.

Palabras Clave. Mobbing, Acoso Laboral, Procedimiento de Tutela Laboral, Ley 20.607.

Fecha de recepción: 3 de julio de 2012.

Fecha de aprobación: 1 de abril de 2013.

** Abogado. Magíster en Derecho, Mención Derecho de la Empresa y del Trabajo, Universidad Católica del Norte. Profesor de la cátedra de Práctica Forense I y II, Facultad de Ciencias Jurídicas, Universidad Católica del Norte, Sede Coquimbo. Profesor de las cátedras de Derecho Económico I y Derecho de Sociedades, Facultad de Ciencias Jurídicas y Sociales, Universidad Central, Sede La Serena. Correo electrónico: jave_56@hotmail.com

1 El presente trabajo está basado en un extracto de la investigación realizada por el autor para la obtención de su grado de Magíster en Derecho, por la Universidad Católica del Norte, Sede Coquimbo, bajo la dirección del Dr. Eduardo Caamaño Rojo. 


\title{
¿IS THE PROCEDURE OF FUNDAMENTAL RIGHTS AN ADEQUATE TOOL CONTROL AND PUNISHMENT OF MOBBING? REFLECTIONS FROM THE ENACTMENT OF LAW 20.607
}

\begin{abstract}
Until the enactment of the Law 20,607, published on August 8, 2012, the absence of specific legislation on mobbing in Chile, resulted in many of the responses to determine the solutions to the conflicts produced by mobbing, given by the practical application that the new labor courts have been made in relation to the current regulations of the Labor Code about the action and proceedings about labor tutelage. From this brief analysis, the following problem arises: The labor tutelage proceeding $\dot{c}$ Does it constitute a suitable tool and really enough to control and punish mobbing in our country?. On this basis, and through the analysis of judgments by our labor courts about laboral proceedings applied to mobbing, this paper seeks to clarify if the statement fits or not to our current reality, but also to reflect and value the explicit recognition of mobbing in our Labor Code from the cited legal changes.
\end{abstract}

KEY WORDS: Mobbing, labor tutelage proceeding, Law 20,607.

Sumario: 1) El mobbing o acoso laboral y su caracterización. (1.1) Antecedentes. (1.2) Concepto de mobbing y elementos que lo caracterizan. 2) El procedimiento de tutela laboral como vía de protección de los derechos fundamentales, en especial frente al mobbing. (2.1) El procedimiento de tutela laboral como mecanismo de defensa de los derechos fundamentales inespecificos. (2.2) Aplicación del procedimiento de tutela laboral al acoso laboral: el mobbing versus la vulneración de derechos fundamentales. (2.3) Análisis jurisprudencial de la aplicación del procedimiento de tutela laboral en relación al control y sanción del mobbing. 3) La dictación de la Ley 20. 607 y el reconocimiento expreso del acoso laboral en Chile: alcances y perspectivas futuras. 4) Conclusión. 5) Bibliografía.

\section{1) EL MOBBING O ACOSO LABORAL Y SU CARACTERIZACIÓN}

\section{1) ANTECEDENTES}

El ambiente en que se lleva adelante la relación laboral es uno de los factores más delicados para la correcta consecución de la finalidad intrínseca que, tanto empleador como trabajador, buscan conseguir al vincularse a través de un contrato de trabajo. En gran medida, el tener un buen 
ambiente en donde desarrollar las labores depende del respeto que se deben todos los involucrados en dicha relación, reconociendo en el otro la dignidad propia de todo ser humano, más allá del cargo o función que le corresponda desempeñar al interior de una empresa.

No obstante, cada vez con mayor frecuencia, se advierte un fenómeno que tiende a resquebrajar los cimientos mismos de la adecuada convivencia laboral: el denominado "mobbing", o "acoso laboral", el cual se refiere a una serie de conductas que implican violencia o maltrato psicológico entre los diversos actores de la relación laboral, conductas de las que, en su gran mayoría, la víctima es un trabajador, quien sufre de un proceso vejatorio de su dignidad, a manos de su empleador o de sus propios compañeros de trabajo. Se trata de un fenómeno complejo, que es necesario previamente delimitar de otro tipo de problemáticas que se suelen dar con ocasión de la relación laboral.

Si bien el término "mobbing" fue utilizado originalmente por el etólogo Konrad Lorenz para definir el fenómeno de agresividad colectiva de un grupo de animales en contra de otro, el empleo de dicho vocablo, para referirse específicamente al acoso moral laboral como fenómeno independiente, se remonta a las investigaciones del psicólogo alemán Heinz Leymann, quien delimitó dicho concepto ${ }^{2}$.

En nuestro país, aún no existe la suficiente conciencia ni información acerca de la necesidad de prevenir y sancionar este tipo de conductas, sin perjuicio de lo cual se advierte un preocupante aumento en la incidencia de las mismas, configurándose como uno de los principales riesgos psicológicos para los trabajadores al interior de las empresas.

Sin perjuicio de los nefastos efectos que el mobbing provoca en la salud e incluso en la productividad de las empresas, claramente la dimensión que más evidentemente lesiona, desde el punto de vista jurídico, es la relacionada a ciertos derechos fundamentales, tales como la honra, la vida privada o el derecho a no ser discriminado arbitrariamente. Debido a situaciones como las descritas, ha surgido la necesidad de que la nueva institucionalidad procesal, contenida en el Código del Trabajo con posterioridad a sucesivas modificaciones legales, contemple un mecanismo que brinde una adecuada y efectiva tutela jurisdiccional de los derechos fundamentales inespecíficos: el procedimiento de tutela laboral.

A pesar de su reciente aplicación por nuestra judicatura laboral, surge la necesidad de conocer si el procedimiento de tutela laboral constituye actualmente una herramienta adecuada y suficiente para el control y sanción del mobbing, o si es recomendable una regulación jurídica específica

2 Arastey Sahun, María Lourdes (Coordinadora) y Gimeno Lahoz, Ramón (Relator) (2006) Conclusiones del Seminario: Los limites del Mobbing. Su deslinde de figuras afines. Disponible en: http://www.sociedadvascadevictimologia.org/adjuntos/Mobbing.pdf [fecha de visita 2 de agosto de 2011], p.3. 
y expresa sobre la materia. A esta interrogante es a la que se intentará dar respuesta a través de la presente investigación, finalizando con algunas reflexiones en torno a las reales implicancias del reconocimiento del acoso laboral en nuestro Código del Trabajo, a partir de la publicación de la ley 20.607 .

\section{2) CONCEPTO DE MOBBING Y ELEMENTOS QUE LO CARACTERIZAN}

La palabra "mobbing" es un vocablo de origen anglosajón, que proviene del verbo inglés "to mob", que implica la idea de acosar, atacar en masa. Es un término que, utilizado en un sentido genérico demasiado extendido, para hacer alusión a cualquier conflicto interpersonal, puede resultar equívoco. La palabra "mobbing" ha dado paso a otras voces que intentan aludir al mismo fenómeno, tales como bossing y bullying. En habla hispana, se suele denominar a este fenómeno como "acoso moral", "acoso laboral", "hostigamiento psicológico", "hostigamiento moral", "terrorismo psicológico", "psicoterror profesional", "acoso ambiental", "linchamiento laboral", "violencia psicológica", "forma de estrés laboral", "síndrome de chivo expiatorio", "presión laboral tendenciosa" 3 .

Al intentar conceptualizar al mobbing, lo primero que debemos distinguir es que, tratándose de un fenómeno emanado originalmente desde la psicología, tendremos conceptos del acoso moral laboral propios de dicha disciplina, y conceptos jurídicos propiamente tales.

Como se adelantó, quien intentó dar una definición precisa del mobbing como riesgo psicosocial relacionado al lugar de trabajo, fue el psicólogo alemán Heinz Leymann, quien acotó dicho concepto en los siguientes términos:

"El mobbing o terror psicológico en el ámbito laboral consiste en la comunicación hostil y sin ética, dirigida de manera sistemática por uno o varios individuos contra otro, que es asi arrastrado a una posición de indefensión y desvalimiento, y activamente mantenido en ella. Estas actividades tienen lugar de manera frecuente (como criterio estadistico por lo menos una vez a la semana) y durante largo tiempo (por lo menos seis meses). A causa de la elevada frecuencia y duración de la conducta hostil, este maltrato acaba por resultar en considerable miseria mental, psicosomática y social" 4 .

Arastey/Gimeno (2006) 3.

Leymann, Heinz, citado en: Torres Mesías, Cesar y Otazo Carrasco, Óscar (2005) Acoso Psicológico Laboral. Memoria para optar al grado de Licenciado en Ciencias Jurídicas y Sociales. Universidad de Chile. Santiago de Chile: Inédita. 583 pp. Disponible en: www.cybertesis.uchile.cl/tesis/uchile/2005/de-torres c/pdfAmont/de-torres c.pdf [Fecha de visita: 22 de julio de 2011], p.10. 
Por su parte, Marie-France Irigoyen, psiquiatra francesa, define el acoso laboral como "cualquier manifestación de una conducta abusiva y, especialmente, los comportamientos, palabras, actos, gestos y escritos que puedan atentar contra la personalidad, la dignidad o la integridad física o psíquica de un individuo, o que puedan poner en peligro su empleo, o degradar el clima de trabajo" 5 .

También destaca el concepto de mobbing que entrega Ińaki Piñuel y Zabala, profesor de la Universidad de Alcalá de Henares, para quien el acoso laboral es "el deliberado y continuado maltrato moral y verbal que recibe un trabajador, hasta entonces válido, adecuado, o incluso excelente en su desempeño, por parte de uno o varios compañeros de trabajo (incluido muy frecuentemente el propio jefe), que buscan con ello desestabilizarlo y minarlo emocionalmente con vistas a deteriorar y hacer disminuir su capacidad laboral o empleabilidad y poder eliminarlo asi más fácilmente del lugar y del trabajo que ocupa en la organización" 6 .

En cuanto a conceptos emanados desde el ámbito jurídico, se puede constatar que no todos los países contemplan regulaciones en sus ordenamientos acerca del mobbing, y asimismo, no todos han optado por definir el fenómeno, salvo ciertas excepciones. Cabe mencionar entre estas últimas, por vía ejemplar, el caso de una ley dictada en la región italiana de Lazio, de fecha 14 de marzo de 2001, denominada "Disposición para prevenir y combatir el fenómeno del mobbing en el lugar de trabajo", cuyo artículo 2 define el acoso moral laboral como "las acciones y comportamientos discriminatorios o vejatorios prolongados en el tiempo, en el lugar de trabajo y dirigidos hacia trabajadores por cuenta ajena, públicos o privados, y realizados por el empresario o por otros compañeros" 7 .

En nuestra doctrina, el profesor Claudio Palavecino Cáceres define al acoso psíquico en el trabajo como "los actos de agresión, múltiples y reiterados en el tiempo, instigados o ejecutados por el empleador, sus representantes y/o por uno o más compañeros de trabajo, que tienen como consecuencia producir un ambiente laboral degradante y dañino para la víctima"8. Por su parte, los profesores Sergio Gamonal y Pamela Prado, han conceptualizado al mobbing como "un proceso conformado por un conjunto de acciones

\footnotetext{
Torres/Otazo (2005) 11.

Piñuel y Zabala, Iñaki, citado en: López Cabarcos, M.Angeles y VÁsquez Rodríguez, Paula (2003) La ley al servicio de la víctima de Mobbing. Disponible en: http://www.ucm.es/ cont/descargas/documento33089.pdf [fecha de visita 22 de julio de 2011], p.74.

7 Medeiros de Oliveira, Flavia (2005) El Acoso Laboral. Tesis doctoral. Valencia: Universitat de Valencia. 720 pp. Disponible en: http://tdx.cat/bitstream/handle/10803/9674/flavia. pdf?sequence $=1$ [fecha de visita 22 de julio de 2011], p.86.

8 Palavecino CÁceres, Claudio (2004). "La protección contra el Acoso Psíquico Laboral en el ordenamiento jurídico chileno". Revista de Derecho (Valdivia), Vol. XVII, pp. 63-89. Disponible en: http://www.scielo.cl/scielo.php?pid=S0718-

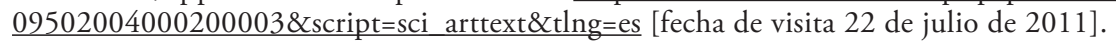


$u$ omisiones, en el ámbito de las relaciones laborales públicas y privadas, en virtud de las cuales uno o más sujetos acosadores crean un ambiente laboral hostil e intimidatorio respecto de uno o más acosados, afectando gravemente su dignidad personal y dañando la salud del o los afectados con miras a lograr distintos fines de tipo persecutorio"?.

De lo dicho, puede desprenderse que conceptualizar el mobbing no es una tarea en la cual pueda bastarnos solamente el Derecho, sino que necesariamente, al igual que lo ocurrido con su prevención, necesariamente implica una labor de un marcado carácter interdisciplinario. De suyo, se trata de un fenómeno en que intervienen una multiplicidad de factores de diversa naturaleza, lo cual ha ocasionado que algunos ordenamientos regulen explícitamente este fenómeno y lo definan, mientras otros dejan dicha tarea reservada a los órganos jurisdiccionales. En este orden de cosas, el rol del Derecho del Trabajo es intentar brindar mecanismos para conseguir la represión y sanción de las conductas constitutivas de acoso laboral, evidenciando su antijuridicidad, y su indudable carácter de ilícito laboral.

En igual sentido, intentar aunar criterios a la hora de determinar los elementos comunes que caracterizan las conductas constitutivas de mobbing, es una faena compleja. Dicha tarea no es baladí, toda vez que, siendo tan amplias las nociones que de este fenómeno han dado las diversas disciplinas, se corre el riesgo de confundir el acoso moral laboral con otro tipo de conductas similares, mas no de idéntica naturaleza. Este problema es de especial importancia para la labor de jueces y abogados, quienes poseen elementos escasos y difusos para configurar con certeza las hipótesis de conductas realmente constitutivas de mobbing. En este sentido, Ramón Gimeno Lahoz resume esta problemática desde la realidad de los foros españoles, haciendo ver que "existiendo el problema laboral, existiendo un clamor social para su sanción, no hay una norma que haya sido modificada para ello, no existe una definición legal de lo que es el mobbing o el acoso moral, y lo que es más grave, no existe una definición doctrinal del concepto que sea comúnmente aceptada, ni a nivel nacional, ni a nivel internacional"10.

Para graficar lo recién expuesto, podemos constatar la multiplicidad de elementos que los diversos autores postulan como los denominadores comunes que permiten identificar al mobbing. Algunos resumen los elementos del acoso laboral en los siguientes:

9 Gamonal Contreras, Sergio; Prado López, Pamela (2006) El Mobbing o Acoso Moral Laboral. Santiago de Chile: Editorial LexisNexis, pp. 22-23.

10 Gimeno Lahoz, Ramón (2004) La Presión Laboral Tendenciosa (Mobbing). Tesis doctoral. Girona: Universitat de Girona. 535 pp. Disponible en: http://www.opas.org.br/gentequefazsaude/bvsde/bvsacd/cd49/presion.pdf [fecha de visita 30 de junio de 2011], p.28. 
- Un proceso de violencia que consta de una serie de etapas (principio del acoso, apertura del conflicto, intervención de los superiores, y finalmente abandono del empleo), y

- Relación asimétrica entre dos partes, en la que una de ellas se extralimita en el ejercicio de su poder ${ }^{11}$.

Otros, consideran como los elementos comunes al mobbing la reunión de las siguientes circunstancias:

- Una serie de conductas agresivas.

- Reiteración en el tiempo de dichas conductas.

- Los sujetos que intervienen: acosador, víctima y entorno.

- El lugar en que se lleva a cabo el mobbing (lugar de trabajo).

- Finalidad y resultado de las conductas agresivas (degradar el ambiente de trabajo, y causar daño físico o psíquico a la salud de la víctima, respectivamente) $)^{12}$.

Para los profesores Sergio Gamonal y Pamela Prado, el acoso moral laboral se caracteriza por los siguientes factores:

- Constituye una situación que se produce en la órbita de las relaciones laborales.

- Está conformado por un conjunto de comportamientos desplegados desde un sujeto acosador(es) en contra de uno o más sujetos (víctimas o acosados).

- Se configura como un proceso, que puede tener distintas fases (claramente diferenciadas o no), pudiendo tratarse de un conjunto de comportamientos por acción u omisión.

- El efecto del acoso moral es producir un ambiente laboral hostil para la víctima y denigratorio de su dignidad de persona, lo que redunda en diversos dańos para su salud.

- La finalidad del acoso moral puede ser de diversa índole (por ejemplo, obtener la renuncia forzada del acosado, buscar una situación propicia para obtener su posterior despido, conseguir que renuncie a la defensa jurídica de sus derechos, etc. ${ }^{13}$.

De este modo, como corolario, podemos desprender de las citadas opiniones doctrinarias que el mobbing o acoso laboral posee los siguientes elementos que lo identifican:

a) Constituye un proceso: una acción aislada, por mucho que sea atentatoria de los derechos fundamentales, no constituye per se inmediatamente acoso laboral.

\footnotetext{
11 Jefferson Cerda, Marcela (2004) El Acoso Psicológico en el Trabajo. Su trato y reconocimiento en el Derecho Chileno. Tesis para optar al grado de Licenciado en Ciencias Jurídicas, Universidad Católica de Temuco. 55 pp. Disponible en: http://biblioteca.uct.cl/tesis/marcelajefferson/tesis.pdf [fecha de visita 22 de julio de 2011], p.14.

12 Torres/ Otazo (2005) 14.

13 Gamonal/Prado (2006) 19-21.
} 
b) Los sujetos involucrados deben estar vinculados por una relación laboral, pudiendo producirse el acoso desde el empleador a sus trabajadores, o entre compañeros de trabajo (también es posible el acoso de trabajadores a sus superiores, aunque no es tan común).

c) La finalidad del mobbing, si bien puede ser muy diversa dependiendo de los casos, siempre implica aislar y degradar a la víctima dentro de su ambiente laboral.

d) El resultado del acoso, más allá de las particularidades dependiendo de quién lo sufra, implica una serie de daños en su salud, en sus condiciones de trabajo, e incluso en su calidad de vida.

2) El PROCEDIMIENTO DE TUTELA LABORAL COMO VÍA DE PROTECCIÓN DE LOS DERECHOS FUNDAMENTALES, EN ESPECIAL FRENTE AL MOBBING

\section{1) EL PROCEDIMIENTO DE TUTELA LABORAL COMO MECANISMO DE DEFENSA DE LOS DERECHOS FUNDAMENTALES INESPECÍFI- COS}

Como bien señala Ugarte, la subordinación presente en la relación laboral la acerca, más que a una típica relación de derecho privado entre relativamente iguales, a una relación jerárquica más bien parecida a la del derecho público, constituyendo un escenario propicio para vulneraciones de los derechos fundamentales de la parte más débil y subordinada jurídicamente ${ }^{14}$. Frente a esta realidad, si bien es cierto que, incluso desde antes de la reforma procesal laboral, los derechos fundamentales inespecíficos de los trabajadores fueron progresivamente revalorizados al interior de la empresa, aún se podía constatar el poco respecto que en la práctica se daba a los mismos, principalmente por parte de los empleadores.

Uno de los factores que condicionaba esta problemática, era la carencia de mecanismos de tutela judicial efectiva que les confirieran una real vigencia a dichas garantías: es precisamente en este escenario en el cual se dicta la ley 20.087, introduciendo, entre otras modificaciones, el procedimiento de tutela laboral.

Desde un comienzo, la incorporación del procedimiento de tutela laboral fue bien recibido por la doctrina laboralista (más allá del hecho de presentar, como consecuencia de ser producto de una negociación política, una serie de falencias en su diseño final), y fue considerado por

14 Ugarte Cataldo, José Luis (2007). "La tutela de derechos fundamentales y el derecho del trabajo: de erizo a zorro". Revista de Derecho (Valdivia), Vol. XX, N², p.59. 
muchos como la herramienta mediante la cual al fin los derechos fundamentales tendrían eficacia directa ${ }^{15}$. Si examinamos las ventajas que este procedimiento significó para los trabajadores, es evidente que implica un avance en relación a la situación anterior: legitimación activa ampliada, incorporación de la garantía de indemnidad entre los derechos fundamentales tutelados, el alivio en la carga probatoria del trabajador, a través del sistema de prueba indiciaria, y la necesidad de que el juez confeccione una sentencia definitiva compleja, que incluya decisiones que satisfagan el cúmulo de pretensiones que una demanda de tutela implica.

\section{2) APLiCACIÓN DEL PROCEDIMIENTO DE TUTELA LABORAL AL ACOSO LABORAL: EL MOBBING VERSUS LA VULNERACIÓN DE DE- RECHOS FUNDAMENTALES}

Actualmente, es un hecho generalmente aceptado que la vía más idónea para acceder a tutela judicial efectiva por casos de acoso laboral es precisamente el procedimiento de tutela laboral, lo que se ve refrendado en la práctica judicial. Ello se explica por varias razones, cuyo denominador común es que dicho procedimiento permite abordar con claras ventajas la protección de las víctimas de acoso laboral:

- El procedimiento de tutela laboral es aquel que resulta más pertinente a la protección contra el mobbing, desde el punto de vista de su objetivo específico: según lo dispuesto en el artículo 485 del Código del Trabajo, entre los derechos fundamentales cautelados por este procedimiento se encuentran precisamente algunos de los que suelen ser más vulnerados a través del mobbing, como la integridad física y psíquica (siempre que la vulneración sea consecuencia directa de actos ocurridos en la relación laboral), la vida privada, la honra, la inviolabilidad de toda forma de comunicación privada, la libertad de opinión, el derecho a no ser discriminado arbitrariamente, y finalmente la garantía de indemnidad.

- Por otra parte, una de las principales ventajas que implica este procedimiento, es paliar la difícil situación procesal que enfrenta el trabajador acosado al momento de comprobar la real motivación y finalidad que existe detrás de las conductas constitutivas del acoso, las que suelen ser muy fáciles de disfrazar como malos ambientes laborales o simplemente como situaciones objetivas que no involucran el afán destructivo hacia la víctima, elemento propio del mobbing. Esta ventaja viene dada por la introducción del mecanismo de la prueba in-

15 Una interesante opinión disidente, desde la perspectiva del constitucionalismo, podemos encontrar en: Silva Irarrázaval, Luis Alejandro (2011). "Supremacía constitucional y tutela laboral”. Revista de Derecho (Valdivia), Vol. XXIV, N 1, pp. 31-48. 
diciaria, consagrado en el artículo 493 del Código del Trabajo, según el cual, "cuando de los antecedentes aportados por la parte denunciante resulten indicios suficientes de que se ha producido la vulneración de derechos fundamentales, corresponderá al denunciado explicar los fundamentos de las medidas adoptadas y de su proporcionalidad".

Respecto a la prueba indiciaria, Gamonal afirma que se la puede definir como "un estándar probatorio que exige una prueba minima de la vulneración de un derecho fundamental del trabajador subordinado, para que sea el empleador quien deba justificar la licitud de su actuación"16. De este modo, siendo capaz la víctima del acoso de acreditar la ocurrencia de acciones u omisiones que denoten o hagan presumir al menos la ocurrencia de la vulneración de los derechos fundamentales, debe ser el empleador quien justifique la proporcionalidad y necesidad de los actos supuestamente lesivos. Esta disminución de la carga probatoria es particularmente beneficiosa en el caso del acoso laboral, al punto que, de no existir la norma aludida, quizás en la mayoría de los casos sería prácticamente imposible evidenciar la finalidad eminentemente destructiva de actos u omisiones supuestamente neutros, a través de los cuales se configura el mobbing. - Además de lo dicho, el procedimiento de tutela laboral provee de una protección completa al trabajador vulnerado. En efecto, el artículo 495 del Código del Trabajo consagra una tutela inhibitoria (produciendo el cese inmediato de las conductas bajo apercibimiento de multa, pudiendo repetirse dicha medida hasta obtener el cumplimiento), una tutela restitutoria (debiendo velar el juez para que la situación se retrotraiga al estado inmediatamente anterior a producirse la vulneración denunciada), y una tutela resarcitoria (debiendo indicar el juez concretamente las medidas a que se encuentra obligado el infractor, destinadas a obtener la reparación de las consecuencias de las conductas vulneradoras, comprendidas las indemnizaciones que procedan, punto que es interesante, pues dentro de estas se comprendería la indemnización por daño moral).

No obstante lo recién dicho, en lo que va de vigencia del procedimiento de tutela laboral, no se aprecia un gran número de fallos que acojan la tutela invocando como fundamento la ocurrencia del mobbing. El Informe Anual sobre Derechos Humanos en Chile 2011, nos da una idea clara de cómo se ha enfrentado la conjunción tutela laboral - acoso laboral por parte de nuestros tribunales:

"No obstante, del funcionamiento de la nueva justicia del trabajo es posible sostener que los casos que se conocen y se fallan son relativamente escasos, cuestión que estaria explicada por la falta de un concepto legal más preciso

16 Gamonal Contreras, Sergio (2008) El procedimiento de tutela de derechos laborales. Santiago de Chile: Editorial LegalPublishing Chile, p.28. 
que ayude a los jueces a aplicar y proteger a los trabajadores, como también por gran cantidad de avenimientos y acuerdos que impiden la existencia masiva de fallos en la materia.

Sobre la falta de un concepto legal preciso, parece explicar la tendencia de los jueces de tutela laboral a evitar pronunciarse sobre el acoso moral laboral en cuanto tal. Lo consiguen desechando por cuestiones de forma las demandas de tutela laboral en las que se reclama acoso, y pronunciándose en su lugar respecto de la acción subsidiaria intentada por el o la demandante, que es la de despido injustificado"l7.

La fórmula más comúnmente utilizada para plantear este tipo de casos ante los juzgados del trabajo, resulta ser accionar, en lo principal, a través de tutela laboral, y, subsidiaria o conjuntamente, reclamando despido injustificado o despido indirecto, según el caso, dado lo prescrito por el artículo 489 , inciso séptimo ${ }^{18}$. Ahora bien, si nos abocamos al examen de cómo abordar estratégicamente una demanda o denuncia por mobbing a través del procedimiento de tutela laboral, resulta de gran relevancia tener presente una particularidad que se ha venido produciendo en la manera en que los tribunales resuelven este tipo de materias: más que poner énfasis en la constatación del mobbing, los sentenciadores buscan corroborar la existencia o no de las vulneraciones a los derechos fundamentales denunciadas, supuestamente materializadas a través del acoso laboral. Ello no deja de ser una solución adecuada al efecto de lograr el fin último de la acción de tutela laboral, cual es reparar las lesiones de derechos fundamentales, y sancionar al infractor, principalmente si consideramos la dificultad que implica pronunciarse sobre un fenómeno como el mobbing, que no cuenta con un concepto legal, ni tan siquiera con un conjunto de elementos reconocidos normativamente, que permitan establecer con certeza su ocurrencia. Frente a esta incertidumbre, el buscar acreditar directamente la vulneración de los derechos fundamentales resulta siempre un estándar objetivo, y que cuenta con el reconocimiento normativo expreso del artículo 485 antes aludido.

Consecuencia de lo anterior, cabe preguntarse: ¿cuán útil puede resultar, finalmente, invocar el mobbing en una demanda por tutela laboral? La pregunta no es antojadiza, si se tiene presente que en ocasiones los tribunales han rechazado acciones de tutela laboral por entrar al análisis del acoso laboral invocado, y no lograr dar por acreditados los elementos

17 Ugarte Cataldo, José Luis (2011). "Derechos humanos en la relación de trabajo: el caso del acoso laboral”. En: Contesse Singh, Jorge (director y editor general): Informe anual sobre derechos humanos en Chile 2011. Santiago de Chile: Ediciones Universidad Diego Portales, Pp. 265-283. Disponible en: http://www.derechoshumanos.udp.cl/informe-anual-sobrederechos-humanos-en-chile-2011/ [fecha de visita 15 de noviembre de 2011], p.281.

18 En ocasiones también se ha demandado en procedimiento de tutela laboral conjuntamente con una acción de indemnización por daño moral. 
propios de este fenómeno, elementos que en cada caso dependían del juzgador, toda vez que, hasta la dictación de la ley 20.607, nuestro ordenamiento jurídico laboral no contemplaba una definición legal que vinculara al tribunal a la hora de pronunciarse sobre el particular. Este riesgo queda de manifiesto, por vía de ejemplo, en lo ocurrido en la sentencia dictada por el Juzgado de Letras del Trabajo (en adelante JLT) de Antofagasta, en causa RIT T-13-2009 ${ }^{19}$, en la cual la acción de tutela, se rechaza, debido a que el tribunal estima que, sin perjuicio que el demandante acreditó hechos que pudieran a priori constituir indicios de vulneración de las garantías de integridad psíquica y honra del trabajador, la demandada fue capaz de dar justificaciones suficientes, a juicio del tribunal, para explicar las acciones denunciadas. Si bien el fallo pudiera resultar interesante, porque el tribunal utiliza la expresión "acoso laboral”, el problema es que no define la misma, lo cual es relevante, considerando que el tribunal utiliza la expresión cuando declara que no existió tal acoso, pero no enuncia cuáles serían los elementos del mismo ("presupuestos fácticos", como el mismo tribunal les denomina):

"Que, en lo que concierne a la demandada, y las explicaciones que esta ha proporcionado para justificar los fundamentos de cada una de las acciones detalladas en el motivo precedente, el Tribunal ha llegado a la convicción que estas son suficientes para tal efecto, de manera tal que no se ha configurado la vulneración de derechos fundamentales al modo como lo ha planteado el actor, no dándose en consecuencia los presupuestos fácticos del mobbing o acoso laboral denunciado. "(Considerando decimocuarto).

Esto es especialmente grave, si se considera que el mismo tribunal fijó como primer hecho a probar el siguiente: "Efectividad de haber sufrido el actor actos de acoso laboral, en su caso, naturaleza de los mismos y circunstancias de ello".

De este modo, mientras nuestra legislación no había definido expresamente al acoso moral laboral, ni establecía claramente qué condiciones, requisitos o elementos deben cumplirse para estar en presencia del mobbing, una alternativa adecuada a la finalidad de protección de las víctimas, era enfocar los casos sobre este fenómeno poniendo énfasis directamente en la vulneración de los derechos fundamentales.

19 Juzgado de letras del Trabajo de Antofagasta. 18 de enero de 2010. Rit T-13-2009. "Morales Iriondo, Pedro c/ Productos Fernández". Disponible en: http://sentenciasreformalaboral.blogspot.com/2010/02/tutela-sjl-antofagasta-18012010-rechaza.html [fecha de visita 8 de agosto de 2011]. 


\section{3) ANÁLISIS JURISPRUDENCIAL DE LA APLICACIÓN DEL PROCEDI- MIENTO DE TUTELA LABORAL EN RELACIÓN AL CONTROL Y SAN- CIÓN DEL MOBBING}

El análisis que se pasa a exponer pretende determinar cuál ha sido el rol del procedimiento de tutela laboral en el control y sanción del mobbing, y en función de ello, determinar si constituye una herramienta bastante a dicho efecto.

Como cuestión preliminar, para evaluar el rol protector del procedimiento de tutela laboral en relación a los derechos fundamentales inespecíficos de los trabajadores, conviene no perder de vista la visión del mismo como una garantía jurisdiccional, a través de la cual se debe pretender la realización, a su vez, de dos importantes derechos fundamentales: el derecho al debido proceso y el derecho a la tutela judicial efectiva. La conjugación en la consecución de ambos, o lo que, en palabras de Carlos Alberto Álvaro de Oliveira, debiese ser una tutela jurisdiccional adecuada (en donde adecuación significa proporcionalidad entre efectividad y seguridad), es un delicado equilibrio del que no debe quedar exento el análisis del procedimiento en estudio: "El derecho fundamental de acceso a la jurisdicción se traduce entonces en el poder de exigir del órgano judicial, en tiempo razonable, el desarrollo completo de sus actividades, tanto decisorias, con emisión de un pronunciamiento procesal o de mérito sobre el objeto de la pretensión procesal, como que pueda ser realizado efectivamente desde el punto de vista material. Todo eso debe conformarse al concepto de adecuación, con la proporcionalidad necesaria entre el derecho fundamental a un proceso justo $y$ el derecho fundamental a una tutela jurisdiccional efectiva y adecuada" 20 .

De este modo, la efectividad del proceso implica la posibilidad seria y real de obtener del juez una decisión de mérito, más allá de los obstáculos formales que impidan dicha finalidad, para lo cual la tutela jurisdiccional debe adaptarse a la naturaleza de las situaciones subjetivas tutelables, de modo que sea totalmente satisfecha la necesidad de protección contenida en la demanda. Todo ello sin lesionar la debida seguridad jurídica, para lo cual se debe ponderar estos dos valores en relación al caso concreto.

A través del análisis de algunos fallos en que se acoge la acción de tutela por acoso laboral, se pretende ilustrar si dicha herramienta procesal cumple con los indicadores antes expuestos.

a) Concepto y elementos configurativos del mobbing: En general, el primer aspecto interesante a analizar en las sentencias que acogen la acción

\footnotetext{
20 Álvaro de Oliveira, Carlos Alberto (2009). "El derecho a la tutela jurisdiccional efectiva desde la perspectiva de los derechos fundamentales". Revista de Derecho (Valdivia), Vol. XXII, $\mathrm{N}^{\circ} 1$, p. 192 .
} 
de tutela laboral por mobbing, es determinar si el sentenciador intenta dar un concepto o definición del acoso laboral, fundamentándolo desde la doctrina laboralista, o al menos, identificando claramente, de la manera más completa posible, los diversos elementos que deben estar presentes para poder configurar dicho ilícito. En caso afirmativo, surge a su vez la interrogante de si ello resulta determinante en la decisión de acoger en definitiva dicha acción. La ausencia de un concepto de acoso laboral, hasta la incorporación de la actual definición al artículo 2 del Código del Trabajo, mediante la modificación propiciada por la ley 20.607, ha resultado de especial relevancia a la hora de determinar la existencia o no de estas conductas.

En causa RIT T-63-2009, por el Segundo JLT de Santiago ${ }^{21}$, la Inspección Provincial del Trabajo de Santiago interpuso denuncia en procedimiento de tutela laboral por reiterados actos de acoso laboral, bajo forma de agresión verbal, en contra de un trabajador durante la ejecución del contrato. Al fundamentar el tribunal su decisión de acoger la acción de tutela, realiza una explicación detallada del fenómeno de acoso moral laboral, relacionándolo con el caso sub lite, y asignándole un rol muy relevante en la solución del conflicto:

"Para dilucidar la materia de estos autos, y en relación a lo dicho anteriormente, se debe recordar la naturaleza del acoso moral laboral o mobbing.

Podemos decir que son actos condenables o explicitamente hostiles dirigidos de modo repetido contra todo asalariado en el lugar de trabajo, se trata de ataques sistemáticos y durante un lapso de tiempo intolerable, sea de modo directo o indirecto que atenta contra la dignidad de la persona y crea un entorno intimidatorio, hostil, degradante, humillante y ofensivo.

La existencia de acoso laboral implica los siguientes elementos: uno objetivo, consistente en la entidad de la conducta, que por si sola y prescindiendo de subjetivas apreciaciones o sensibilidades, debe ser susceptible de provocar la consecuencia degradante, humillante u ofensiva. Otro subjetivo, referido no tanto a la persona que provoca el acoso, y que según la modalidad puede ser uno o varios superiores, iguales, o incluso un grupo de subordinados, sino a la persona acosada, que debe estar individualizada, sin que pueda hacerse extensivo del acoso con carácter general a un grupo de personas, ya que en tal caso nos encontrariamos simplemente ante un ambiente tenso de trabajo. $Y$ un elemento finalista, ya que las conductas en cuestión se orientan a la exclusión laboral del acosado e incluso su anulación social en el ámbito del que se trata.

Cabe indicar, por otra parte, que la figura del acoso moral laboral viene caracterizada, por la sistemática y prolongada presión psicológica que se ejerce

21 Segundo Juzgado de Letras del Trabajo de Santiago. 12 de febrero de 2010. Rit T-63-2009. "Inspección Provincial del Trabajo de Santiago c/CENCOSUD Retail S.A.". Disponible en: http://sentenciasreformalaboral.blogspot.com/2010/02/tutela-2do-jlt-

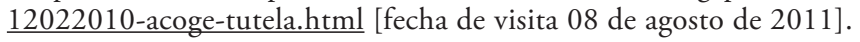


sobre el trabajador (hostigamiento, asedio, vejación, humillación, constante crítica, etc.) en el desempeño de su cometido, causándole un daño psíquico real que le hace perder la posibilidad de una normal convivencia en su propio ámbito profesional. Además, siguiendo a Sergio Gamonal, el resultado objetivo del mobbing es que se produce un ambiente laboral hostil para la victima y denigratorio de su dignidad de persona que redunda en daños a la salud como la depresión, el estrés, o ansiedad. (Considerando noveno).

"(...)En el caso de autos, como ya se dijo, el acoso moral laboral, en sus distintas vertientes y razones, constituye una forma de ataque a la dignidad del trabajador, a través de una conducta desplegada por un sujeto (empleador o sus representantes, en este caso don Victor Muñoz) que se caracteriza por reiterar en el tiempo un hostigamiento a ese trabajador (Marcelo Campos), mediante actuaciones vejatorias o intimidatorias de carácter injusto (groserias y aseveraciones menoscabando su desempeño), con el propósito de lograr una finalidad consistente de modo especifico en minar psicológicamente la resistencia del acosado, y lograr asi de modo efectivo algún objetivo que de otro modo no hubiera conseguido el hostigador.

En el presente caso, aun siendo reiterativo, se declara probado, un conjunto de actuaciones y comportamientos del superior jerárquico del afectado, también trabajador de la empresa demandada, que de modo reiterado y mantenido en el tiempo han ido dirigidos a menospreciar, humillar y desacreditarlo, que le ha provocado un cuadro de angustia y ansiedad lo que ha motivado tener que ser atendido por la Médico Psiquiatra Dra. Gabriela Negrete Lafuente, según certificado médico incorporado y que no ha sido cuestionado, por lo que se configura la vulneración de sus garantias consagradas en el $N^{\circ}$ 1 y 4 del articulo 19 de la Constitución Politica de la República, estos son, derecho a la integridad física síquica y derecho a la honra. "(Considerando duodécimo).

En el fallo comentado, la relevancia que el tribunal asignó al acoso laboral fue el considerarlo como el medio específico a través del cual el demandado ocasionó la lesión de los derechos fundamentales del trabajador, debido a lo cual apreció cuidadosamente las características especiales de este conjunto de conductas como un todo, lo que justificó la extensa explicación citada, que incluyó, como queda dicho, un esbozo de concepto, pero principalmente, evidenciar los elementos que lo configuran, como asimismo sus peculiares características.

Por contrapartida, en sentencia dictada en causa RIT T-20-2010, por el JLT de Iquique ${ }^{22}$, el sentenciador de la instancia utilizó una definición

22 Juzgado de Letras del Trabajo de Iquique. 27 de agosto de 2010. Rit T-20-2010. "Pérez Devia, Duxann P. c/ Serviclínica Iquique S.A.” Disponible en: http://sentenciasreformalaboral.blogspot.com/2010/10/tutela-jlt-iquique-26082010-acoge.html [fecha de visita 03 de diciembre de 2011]. 
de mobbing, concretamente la del psicólogo Heinz Leymann, para determinar si se configuraba el acoso laboral en dicho caso:

"Que, Heinz Leymann, principal artifice de la sensibilización sobre esta materia, definía el moobing como aquel fenómeno en que una persona o grupo de personas ejerce una violencia psicológica extrema de forma sistemática y recurrente, con la finalidad de destruir las redes de comunicación de la victima, destruir su reputación, perturbar el ejercicio de sus labores y lograr finalmente que esa persona acabe abandonando el lugar de trabajo. En consecuencia, a la luz de los efectos biológicos que el acoso laboral produce en las personas, claramente puede entenderse como constitutivo de un atentado en contra de la integridad física y psiquica, toda vez que estos sintomas son de tal entidad, que no los podemos incluir dentro de la normalidad de vaivenes que sufre el ser humano."(Considerando décimo).

"Que, en este orden de ideas, y conforme la definición de "moobing" referida en el considerando décimo de este fallo, cabe agregar que para que exista el acoso laboral, debe existir una presión laboral sobre el trabajador, que se encuentre ligada a otros elementos no laborales, esto es, no solo la exigencia de actuaciones del trabajador en la esfera de sus funciones (cuestión que alega la demandada), sino que sumado a dicha presión se le denigre y menoscabe, produciendo un efecto sicológico en éste. Todos antecedentes que se evidencian para el caso de marras, ya que más allá de las exigencias declaradas por la denunciada, respecto del trabajo que debia realizar el actor, el trato vejatorio que refieren los testigos de la denunciante, sumado a la exclusión del trabajador en forma mediática de sus funciones, esto es, tal como lo señala Arismendi Liendo, se le quitó la responsabilidad de la mantención de los computadores, para entregársela a alguien que se encontraba antes bajo subordinación del actor y disminuyéndolo en cuanto a su capacidad de gestión (episodio de solicitud de dinero relatado por este testigo), sumado a la designación en el cargo de Supervisor de Mantención, del Sr. Tello-que según expresa el absolvente-correspondia a su cargo, hacen verosimiles las alegaciones de la denunciante."(Considerando decimocuarto).

$\mathrm{Si}$ bien resulta destacable el que el tribunal haya incluido referencias a un concepto determinado de mobbing, las consecuencias de comprometer la decisión del caso con una definición en particular de acoso laboral, pueden dar pie a cuestionamientos, más aún cuando, más allá de la cita, no se expliciten de manera más precisa ciertos elementos que deben concurrir para estar en presencia de acoso laboral. En efecto, en el caso comentado, ello permitió que el demandado recurriera de nulidad (Rol 73- 2010, Corte de Apelaciones de Iquique $\left.{ }^{23}\right)$, siendo uno de sus fun-

23 Corte de Apelaciones de Iquique. 4 de octubre de 2010. Rol N 73-10. "Pérez Devia, Duxann P. cl Serviclínica Iquique S.A.” Disponible en: http://cl.microjuris.com/ getContent?reference=MJCH_MJJ25055\&links=[MOBBING] [fecha de visita 8 de agosto de 2011]. 
damentos precisamente la definición de mobbing utilizada, y el hecho de que la sentenciadora no corroboró otros de los requisitos necesarios para estar en presencia del mobbing:

"El recurrente inicia su relato sosteniendo que la Sra. Juez acogió la acción de tutela laboral por vulneración del derecho fundamental del artículo $19 N^{\circ} 1$, inciso primero, de la Constitución Politica de la República, integridad fisica y síquica, e indemnidad del artículo 485 del Código, erróneamente. Indica, luego de citar doctrina, que sin perjuicio de todas las definiciones o conceptos de la figura, en forma unánime se ha establecido que sus características son, existencia de un sujeto activo (perpetrador del acoso), un sujeto pasivo (víctima), ocurrencia en actividades de carácter laboral, presión tendenciosa ilegítima, sistemática y reiterada, que puede tener varios objetivos, pero siempre produce un daño, elementos copulativos. Añade que la sentenciadora no individualiza todos sus presupuestos, se limita a citar una de las definiciones de mobbing, sin considerar un principio de carácter lógico como es el análisis riguroso de una figura doctrinaria que no está definida en la ley, utilizando la de uno de los primeros investigadores y divulgadores de este fenómeno. Heinz Leymann, que dista mucho de ser práctica para su examen desde una perspectiva jurídica, es empleada principalmente en el área de la psicología pedagógica."(Considerando primero, fallo recurso de nulidad).

Finalmente, la Corte de Apelaciones de Iquique desestimó el argumento del recurrente, en orden a criticar la definición de mobbing utiliza$\mathrm{da}$, precisamente porque dicha figura no se encontraba definida en la ley:

"Lo que resta es rechazar el recurso porque pese a las extensas alegaciones del recurrente de nulidad, lo cierto es que en definitiva claramente ataca la forma en que la Sra. Juez valoró las probanzas, por qué eligió unas y no aquellas que él hubiese deseado, cuestión asimilable a un recurso de apelación, no concebido en la materia de que se trata, y lo mismo ocurre con la definición de acoso laboral que la Sra. Juez tiene en cuenta, aspecto éste que ni siquiera pudiera ser revisado desde la perspectiva del medio ordinario de impugnación, si existiera, porque legalmente no se encuentra definido."(Considerando quinto, fallo recurso de nulidad).

Esto último hace reflexionar sobre la necesidad de definir parámetros más objetivos a la hora de considerar los requisitos que deben cumplirse para determinar fehacientemente si un conjunto de conductas hostiles constituyen o no acoso laboral: la ausencia de legislación sobre el particular afecta directamente la posibilidad de una administración de justicia que cumpla con estándares de seguridad y certeza aceptables, como asimismo atenta contra una adecuada y suficiente fundamentación de las decisiones contenidas en las sentencias. Más adelante examinaremos si la modificación que introduce la ley 20.607 satisface este vacío. 
A raíz del contraste evidenciado por los tribunales para acoger la acción de tutela laboral por mobbing, entre el utilizar una particular definición de acoso laboral, o simplemente describir sus elementos configurativos, surge una tercera alternativa: el acoger la acción de tutela simplemente a partir de la constatación de la lesión de los derechos fundamentales denunciada, sin entrar a intentar dar por configurado el acoso laboral. Es curioso que esto es precisamente lo que ocurrió en, una de las más mediáticas causas en donde nuestra judicatura laboral dio una potente señal en contra del mobbing: el caso de acoso discriminatorio de que fuese víctima Nora Melo, trabajadora que fue objeto de dicha práctica debido a profesar públicamente la religión musulmana.

En efecto, en la sentencia dictada en causa RIT T-38-2010 ${ }^{24}$, seguida ante el Primer JLT de Santiago, el sentenciador en ningún momento hace alusión al acoso laboral directamente para fundamentar la decisión, sino que toda la argumentación parte del hecho de considerar producida la lesión de los derechos fundamentales de la trabajadora, por actos de discriminación, y no haberse entregado por parte del empleador, explicaciones suficientes sobre la justificación o proporcionalidad de las medidas empleadas:

"Que conforme lo antes referido la parte demandante ha podido acreditar en autos hechos que constituyen indicios o señales suficientes de un trato diferente a la trabajadora respecto de sus compañeros, fundado especificamente en la religión que esta profesa, lo que se materializaba a través de los insultos que hacian referencia a su credo y en tratamiento que se le daba diariamente al hacer diferencias negativas en cuanto a la hora y consecuencialmente la forma de su descanso, al asignarle un puesto de trabajo alejado de sus compañeros, además de impedirle situaciones tan cotidianas como hablar con los clientes que se comunicaban en un idioma diferente al español, tal como ocurría con el resto de sus compañeros, sin ningún fundamento legitimo para ello, todo lo cual le provocó una depresión severa."(Considerando decimocuarto).

“(...)Que sin perjuicio de lo anterior, tampoco la demandada alegó ni rindió prueba alguna orientada a justificar la proporcionalidad de las medidas adoptadas, en orden a omitir o modificar el horario de descanso de la trabajadora afectada, la designación de cambio de puesto alejado de sus compañeros de trabajo o la prohibición de hablar en árabe, máxime si esta era una conducta habitual entre los supervisores y trabajadores de la demandada, al ser una práctica esporádica, especialmente debido a los servicios

24 Primer Juzgado de Letras del Trabajo de Santiago. 26 de abril de 2010. Rit T-38-2010. "Inspección Provincial del Trabajo de Santiago c/TP Chile S.A.”. Disponible en: http://sentenciasreformalaboral.blogspot.com/2010/04/tutela-jlt-1 ro-santiago26042010-acoge.html [fecha de visita 1 de diciembre de 2011]. 
contratados por Vodafone España a Telepormance Chile."(Considerando decimosexto).

"(...)la conducta desplegada por Rosa Jerez, María Ojeda y David Castro, como superiores de la trabajadora afectada, dentro de su horario de trabajo, en cumplimiento de sus funciones y en representación de la demandada, en orden a tratarla entre otros conceptos como perra musulmana, señalarle que debiera retirarse del pais por la religión que profesaba y discriminarla por dicha situación, produjeron en la trabajadora un menoscabo a su integridad psíquica y el respeto y protección a la honra consagrados en el artículo $19 N^{o} 1$ y 4 del Código del Trabajo, lo primero por cuanto sufrió una depresión mayor y vio disminuir paulatinamente sus competencias en el trabajo y lo segundo al tratársele inadecuadamente y ser objeto de burlas por sus jefes y comentarios por sus pares, solo por el hecho de profesar una religión poco común." (Considerando decimooctavo).

La falta de alusión a un concepto de mobbing en la sentencia comentada, en absoluto constituyó un obstáculo para la adecuada y completa protección de la afectada, y ello hace pensar que no es menor intentar responder a la siguiente pregunta: ¿era realmente necesario definir el acoso laboral en un texto legal?, ¿cuán conveniente pueda resultar esto para una real tutela judicial efectiva de las víctimas de mobbing? Sobre este tema retornaremos en la parte final del presente trabajo.

b) Aligeramiento de la carga probatoria: Como se ha dicho, uno de los beneficios adicionales que el procedimiento de tutela laboral reporta al tratamiento del acoso laboral lo constituye el sistema de prueba indiciaria, que facilita enormemente la acreditación del nexo causal entre las conductas lesivas y los dańos producidos por el mobbing en el trabajador afectado, como se ha podido apreciar en la praxis del foro laboral ${ }^{25}$. En relación al acoso laboral, en la ya citada sentencia dictada en causa RIT T-63-2009, por el Segundo JLT de Santiago, se puede apreciar cómo el tribunal aplica esta herramienta procesal a favor de la víctima del mobbing:

"Que asi las cosas, corresponde determinar si la conducta del señor Victor Muñoz atenta los derechos fundamentales del señor Marcelo Campos. Al respecto, teniendo presente lo dispuesto en el artículo 493 del Código del Trabajo, cuando se alegue que determinada actuación del empleador encubre en realidad una conducta lesiva de derechos fundamentales del afectado, incumbe al autor de la conducta impropia probar que obedece a motivos razonables $y$ ajenos a todo propósito atentatorio a un derecho fundamental. Es decir corresponde al denunciado probar que los hechos motivadores de su actuar,

25 Claro ejemplo de su correcta aplicación, se aprecia en el considerando noveno de la sentencia definitiva dictada en la emblemática causa "Barckhahn con Corporación del Colegio Alemán de Valparaíso”, RIT T-2-2009, seguida ante el Juzgado de Letras del Trabajo de Valparaíso. 
decisión o medida, según el caso, son legitimos o, aun sin justificar su licitud, se presentan razonablemente ajenos a todo móvil atentatorio de derechos fundamentales; no se le impone por tanto la prueba diabólica de un hecho negativo - la no discriminación- sino la razonabilidad y proporcionalidad de la medida o conducta adoptada y su carácter absolutamente ajeno a todo propósito atentatorio de derechos fundamentales.

Se trata, en definitiva, de que el empleador explique objetiva, razonable y proporcionadamente por si mismas su decisión o actuación, eliminando toda sospecha de que actuó en pos de la lesión de un derecho fundamental del trabajador."(Considerando duodécimo).

En el mismo sentido, en el aludido fallo dictado en causa RIT T-202010, por el JLT de Iquique, el sentenciador de la instancia también hizo uso del sistema de la prueba indiciaria a favor del trabajador acosado:

"Que, de la relación temporal de los hechos realizada en el considerando decimoctavo, se desprende que el trabajador fue despido en forma casi coetánea con la comunicación del resultado de la denuncia impetrada por éste ante la Inspección del Trabajo, en tal sentido el articulo 493 del Código del Trabajo, reviste importancia al momento de valorar las probanzas rendidas en juicio, ello, porque si de los hechos se desprenden "indicios suficientes" que den cuenta de la posibilidad de que el despido del trabajador haya sido producto de una represalia del empleador, la carga probatoria de "explicar los fundamentos de las medidas adoptadas y de su proporcionalidad", esto es, del despido, recae sobre éste."(Considerando decimonoveno).

De todos modos, es conveniente tener presente que la prueba indiciaria no siempre constituye una herramienta procesal imprescindible para lograr acreditar la configuración del mismo. Ejemplifica esta afirmación la sentencia dictada en causa RIT T-306-2010, seguida ante el Segundo JLT de Santiago ${ }^{26}$, en donde el tribunal logra una plena convicción acerca de la ocurrencia de las conductas lesivas:

"Conforme a lo anterior, es necesario determinar si la demandada cumplió con la exigencia probatoria exigida por el artículo 493 del Código del Trabajo, esto es la existencia de indicios suficientes de la vulneración alegada. Dicha reducción probatoria a favor del trabajador es parte fundamental de la reforma procesal laboral que persigue la tutela judicial efectiva de los derechos de los trabajadores $y$, en concreto, la protección integral hacia la parte más débil ante el difícil escenario probatorio en que se encuentra el trabajador al momento de efectuar una denuncia por violación o lesión de derechos fundamentales, dada la posición favorable que tiene el empresario sobre la prueba,

26 Segundo Juzgado de Letras del Trabajo de Santiago. 14 de enero de 2011. Rit T-306-2010. "Medina Burgos, Ximena Noemí c/Universidad Tecnológica de Chile INACAP”. Disponible en: http://blog.bligoo.cl/content/view/1286669/SENTENCIA-DEACOSO-MORAL-O-MOBBING-enero-2011.html [fecha de visita 4 de noviembre de 2011]. 
por la proximidad y dominio que tiene sobre ella en la mayoría de los casos. Sin embargo, la doctrina, en su mayoria, ha planteado que no se trata de una inversión del onus probandi, sino que solo se alivia la posición del trabajador exigiéndole un principio de prueba por el cual acredite indicios de la conducta lesiva, esto es, acredite hechos que generen la sospecha fundada, razonable, de que ha existido esta lesión. Una acertada calificación de esta técnica efectuada por el Tribunal Constitucional Español (de cuyo desarrollo jurisprudencial la LPL de ese pais toma la figura) señala que lo que se debe aportar son datos fácticos suficientemente contrastados que permitan establecer una cierta presunción sobre la existencia de la alegada discriminación o lesión del derecho fundamental, razonables indicios. En la especie tales datos fácticos superan largamente la actividad probatoria minima exigida por ley a la parte y se situan en el terreno de la convicción plena desde antecedentes que en conjunto asientan los hechos postulados (y no solo allegan un principio de prueba) y el marco de un escenario constante y de conductas regulares, develan en el carácter del agente que ejecuta el hostigamiento una personalidad iracundia, desmedida en el trato, prejuicioso (condición femenina, condición social originaria) incompatible con la dignidad de la persona."

El fallo comentado confirma lo afirmado por Ugarte, quien, precisando las posibilidades de la aplicación de la prueba indiciaria en el procedimiento de tutela laboral, señala: “...es perfectamente posible que no sea necesario aplicar la regla de juicio contenida en el articulo 493 C. Trab. Más precisamente, en dos casos opuestos: i) el trabajador logró la prueba del hecho lesivo mediante la aportación de prueba directa sobre el hecho; o ii) el empleador logró acreditar hechos constitutivos de una justificación objetiva y proporcionada de la conducta. En estos casos, el hecho de la conducta lesiva no se encuentra incierta o dudosa, sino todo lo contrario: hay certeza probatoria de que ella ocurrió o de que, por el contrario, no es efectiva"27.

c) Tutela inhibitoria, resarcitoria y restitutoria: Resta, finalmente, analizar quizás el aspecto más esencial, cuando se desea determinar la real efectividad del procedimiento de tutela laboral en relación a la protección de las víctimas del mobbing: las medidas concretas adoptadas por nuestros tribunales laborales para impedir, sancionar, resarcir y prevenir dichas conductas. En este aspecto, no se puede desconocer que los juzgados del trabajo, al acoger acciones de tutela por mobbing, han logrado cumplir con los objetivos recién señalados, estableciendo precedentes que dan una clara señal en orden a reprimir este ilícito laboral.

En relación a la tutela inhibitoria, los fallos que acogen la tutela por mobbing transversalmente han sido firmes en ordenar el cese inmediato

27 Ugarte Cataldo, José Luis (2009). "Tutela laboral de derechos fundamentales y carga de la prueba”. Revista de Derecho de la Pontificia Universidad Católica de Valparaíso, Vol. XXXIII, pp. 215-228. Disponible en: http://www.scielo.cl/pdf/rdpucv/n33/a05.pdf [fecha de visita 15 de abril de 2011], p.222. 
de los actos de hostigamiento en contra de las víctimas, bajo apercibimiento de aplicación de multas.

Conviene examinar con mayor detenimiento cómo han satisfecho los tribunales laborales, la tutela restitutoria y resarcitoria. En este sentido, un aspecto que destaca es la satisfacción de las víctimas de acoso laboral en cuanto a sus pretensiones de indemnización por daño moral. Así, en la ya referida sentencia dictada en causa RIT T-306-2010, seguida ante el Segundo JLT de Santiago (en la cual los actos de acoso laboral consistieron, entre otros, en reiterados insultos al honor laboral de la trabajadora demandante, lesión a su calidad profesional, humillaciones, desacreditaciones profesionales, amenazas de despido o cambio en las condiciones laborales o del lugar donde ejerce las actividades, degradaciones, y ridiculizaciones en público), el tribunal emitió un pronunciamiento favorable sobre dicha materia, el cual se encuentra adecuadamente fundamentado:

"...Por el contrario, la demandante logró acreditar fehacientemente en juicio, a través de los documentos antes individualizados, los dichos de sus testigos y su propia absolución, que producto de los hechos denunciados sufre un Trastorno Adaptativo Mixto de origen laboral cuyos sintomas, a juicio de este Tribunal, son propios de un sufrimiento moral, ya que no se podría entender de otro modo, a nivel general, que el solo hecho de sufrir insomnio, trastornos gastrointestinales, anorexia, fobia al lugar de trabajo, entre otros padecimientos, sea considerado como un sufrimiento de carácter moral, que, tal vez, no se reparen naturalmente con un monto de dinero determinado pero le dará a la actora la oportunidad de tener acceso, con mayor facilidad, a las herramientas de tratamiento necesarias para superar dicho trastorno.

(...) Siendo el daño moral sufrido consecuencia directa de la acción ilícita de la demandada, llamada por el ordenamiento a garantizar precisamente el bien que lesiona (articulo 184 del Código del Trabajo) corresponde dar lugar a la demanda en cuanto a la indemnización solicitada, desde que resulta procedente en la lesión de un daño extrapatrimonial ajustar la tutela efectiva al principio transversal al orden normativo que se formula como el deber de reparación integral del daño por quien lo causa.

Existe jurisprudencia superior, en una interpretación extensiva y no literal de la norma general contenida en el artículo 1556 del Código Civil, desde la sentencia de la Corte Suprema de 20 de octubre de 1994 (Revista Derecho $Y$ Jurisprudencia, t.9, sec. 1a, pags. 100 y ss.) que ha recibido las tendencias más modernas acerca del principio resarcitorio anotado, sin que se divise razón alguna para estimar que la interpretación de la norma común sea inaplicable al ámbito del contrato de trabajo. Razonar a favor de la distinción en función de la materia importa consagrar una exégesis inequitativa que niega la reparación del daño y, al mismo tiempo, validar una distinción no amparada por el ordenamiento, que da tutela judicial al daño extrapatri- 
monial causado por un ilícito contractual en una clase de contratos y no en otra" (Considerando decimotercero) ${ }^{28}$.

El considerando citado se hace cargo no tan solo de los efectos laborales de la lesión producto del mobbing, sino también de su adecuado resarcimiento patrimonial, destacando en ello la utilización equitativa de una norma del Derecho Civil, no realizando discriminaciones en función de la naturaleza del contrato, lo que hace que la tutela laboral cumpla con un estándar de garantía jurisdiccional efectiva.

Dentro del mismo ámbito, más allá del resarcimiento patrimonial, los tribunales han decretado medidas ejemplarizadoras para reparar las consecuencias de la lesión de derechos fundamentales, provocadas a través del mobbing. En este punto, conviene citar nuevamente el fallo dictado por el Primer JLT de Santiago a favor de Nora Melo, en el cual se establecieron las siguientes medidas:

"i. - Mantener la asignación de un nuevo supervisor y Project Manager a la trabajadora afectada.

ii. - No asignar como jefes de la señora Nora Melo Iribarren a los señores Rosa Jerez Riveros, Maria Ojeda Laguardia y David Castro Marambio.

iii.- Destinar de los señores Rosa Jerez Riveros, María Ojeda Laguardia y David Castro Marambio a lugar físico de trabajo diferente al de la trabajadora afectada y realizar las gestiones necesarias para evitar cualquier contacto entre ellos.

iv. - Realización de una capacitación no inferior a 6 horas cronológicas para la totalidad de los empleados de la demandada, a fin de desarrollar competencias para un trato adecuado y respetuoso entre pares y subordinados, especialmente en referencia a la convivencia al interior de la empresa, en especial en la relación con las menciones del inciso $4^{\circ}$ del artículo $2^{\circ}$ del Código del Trabajo, dentro del plazo de 3 meses a contar de la fecha en que el presente fallo quede ejecutoriado.

v.- Publicar en los diarios murales del lugar una carta de disculpas a la trabajadora afectada en la cual expresamente reconocerá la existencia de actos discriminatorios y vulneratorios de derechos fundamentales, la cual además deberá adjuntarse a la liquidación de remuneraciones de todos los trabajadores de la misma, todo lo cual deberá cumplirse al mes siguiente de ejecutoriada la presente sentencia definitiva.

vi. - La demandada remitirá a su mandante Vodafone copia autorizada de la presente sentencia definitiva, ordenándose desde ya su otorgamiento, hecho del cual deberá dejar constancia en este proceso en el plazo de 3 meses desde la época en que quede ejecutoriada".

28 Otros fallos en que se acoge satisfactoriamente la pretensión de indemnización del daño moral por mobbing, se pueden encontrar en causa RIT T-1-2009, JLT de Puente Alto, y causa RIT T-38-2010, Primer JLT de Santiago. 
Entre las medidas enunciadas, sobresale aquella que impone al empleador demandado la obligación de realizar capacitaciones a los demás trabajadores acerca del trato respetuoso entre pares. Medidas como esta cumplen además con una finalidad poco desarrollada en relación al control del acoso laboral, como es su prevención, específicamente tratándose del mobbing horizontal.

En el mismo sentido, conviene citar las medidas decretadas por el JLT de Puente Alto en causa RIT T-1-200929, en la cual se condenó al empleador demandado, además de reincorporar a la trabajadora acosada en sus funciones, a "dar un tratamiento psicológico y psiquiátrico" a la misma, como también a "dar excusas públicas en un medio de circulación nacional por la conducta discriminatoria, arbitraria, ilegal, desidiosa, y carente de preocupación mostrada en este caso".

Adicionalmente, también resultan adecuadas para fomentar la prevención del mobbing, medidas como las adoptadas por el sentenciador en el aludido fallo dictado en causa RIT T-63-2009, por el Segundo JLT de Santiago:

"III. - La denunciada vencida deberá, en un plazo prudencial que no exceda los sesenta dias hábiles, incluir en su Reglamento Interno de Orden, Higiene y Seguridad, una referencia expresa y explicita, relativa a la prohibición de quienes desempeñen cargos de jefatura de efectuar maltratos verbales o escritos, de cualquier indole y por cualquier causa a sus subordinados y demás trabajadores, debiendo respetarse siempre la dignidad del trabajador y de sus derechos fundamentales, y dar a conocer dicha regla a todos ellos. Si dicha mención ya se contempla en el respectivo reglamento, se deberá informarla nuevamente a todos los trabajadores por el medio más idóneo que se determine por la misma empresa. Todo ello bajo el apercibimiento ya indicado".

En este caso, se cumple la finalidad de prevenir el mobbing vertical descendente, a través de contemplar prohibiciones en tal sentido, en un instrumento normativo cuyo valor intrínseco es muy relevante, cual es el Reglamento Interno de Orden, Higiene y Seguridad.

Por último, tratándose de las sanciones impuestas a los acosadores, estas no difieren de la normativa general establecida para los restantes casos de lesión de derechos fundamentales, siendo las multas la vía para ello. En relación a esto, a nuestro juicio, no parece proporcional ni adecuada la aplicación de penas pecuniarias a conductas que revisten un especial reproche, dada la cobardía y la invisibilización propias del actuar del acosador, dado su débil efecto disuasivo, menos aún si consideramos

29 Juzgado de Letras de Puente Alto. 10 de marzo de 2010. Rit T-1-2009. "Astorga Guajardo, Amada Beatriz c/Corporación Municipal de San José de Maipo". Disponible en: http://sentenciasreformalaboral.blogspot.com/2010/07/tutela-jlt-puente-alto-

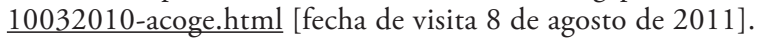


que en países como Francia o España, estas conductas se encuentran tipificadas como ilícitos penales.

\section{3) LA DICTACIÓN DE LA LEY 20. 607 Y EL RECONOCIMIENTO EXPRE- SO DEL ACOSO LABORAL EN CHILE: ALCANCES Y PERSPECTIVAS FU- TURAS}

Dada la importancia que ha adquirido paulatinamente el fenómeno del acoso laboral en nuestro país, como asimismo la necesidad de brindar herramientas que contribuyan a delimitar el concepto como a sancionar las conductas, las diputadas Adriana Muñoz y Ximena Vidal presentaron una moción para tramitar un proyecto de ley que modifique el Código del Trabajo, sancionando las prácticas de psicoterror laboral. A continuación se transcribe el tenor del proyecto, como estaba originalmente concebido:

\section{PROYECTO DE LEY:}

ARTÍCULO ÚNICO.- Agrégase el siguiente Título VII al Capitulo IV del Libro I del Código del Trabajo denominado "De las prácticas que constituyen acoso laboral y de sus sanciones":

\section{Titulo VII}

Articulo 183 bis A.- El acoso laboral, llamado también psicoterror laboral, es una práctica que importa una violación a los derechos esenciales que emanan de la persona humana.

Para efectos de este Código se entenderá por tal, la situación en que el empleador, o uno o más trabajadores, o aquel y uno o más de estos, ejercen o manifiestan por hechos o por dichos una particular forma de violencia psicológica de carácter extremo, premeditadamente o no, con regularidad sistemática y durante un tiempo prolongado sobre otro trabajador en el lugar de trabajo común, con el fin de provocar un menoscabo material y personal en este.

Artículo 183 bis B. - El trabajador, quien hubiere sido víctima de prácticas que den lugar a acoso laboral, deberá denunciarlas en un plazo de 60 dias hábiles contados desde el último acto que las constituya.

Las denuncias sobre acoso laboral podrán ser recibidas por la Inspección del Trabajo respectiva, las que de conformidad a las normas pertinentes, conocerá de ellas pudiendo aplicar las sanciones que a continuación se expresan.

Articulo 183 bis C. - El acoso laboral será penado con multa a beneficio fiscal de 10 a 50 a UTM, sin perjuicio de las acciones que el trabajador pudiera ejercer en conformidad a las reglas generales. 
Artículo 183 bis D. - La comisión de un acto que importare una práctica de acoso laboral debidamente acreditada, se entenderá como un incumplimiento grave a las obligaciones que impone el contrato.

En consecuencia, el trabajador quien hubiere sido víctima de acoso laboral, podrá ejercer el derecho que se le confiere en el artículo 171, cuando el acosador laboral sea el empleador, o quien lo represente en conformidad al artículo 4 de este Código 30 .

Luego de un extensa tramitación en el parlamento, y de múltiples modificaciones, finalmente, el 8 de agosto de 2012 fue publicada la Ley $\mathrm{N}^{\circ} 20.607$, la cual modifica el Código del Trabajo, incorporando por primera vez el reconocimiento y sanción expresa de las conductas de acoso laboral:

- En primer lugar, introduce en el inciso $2^{\circ}$ del artículo 2 del Código del Trabajo -referente a la dignidad de la persona- el concepto de acoso laboral, indicando que se entiende por tal, "toda conducta que constituya agresión u hostigamiento reiterados, ejercida por el empleador o por uno o más trabajadores, en contra de otro u otros trabajadores, por cualquier medio, y que tenga como resultado para el o los afectados su menoscabo, maltrato o humillación, o bien que amenace o perjudique su situación laboral o sus oportunidades en el empleo".

- Por otra parte, se modifica el artículo $160 \mathrm{~N}^{\circ} 1$ del Código del Trabajo, al incluir como nueva causal de caducidad del contrato de trabajo, en su letra $\mathrm{f}$ ), las "conductas de acoso laboral".

- Finalmente, se introducen dos modificaciones al artículo 171 del Código: tratándose del despido indirectos, se establece que si se aplica la causal del artículo $160 \mathrm{~N}^{\circ} 1$ letra $\mathrm{f}$ ), es decir conducta de acoso laboral por parte del empleador, el trabajador podrá demandar conjuntamente otras indemnizaciones a que tenga derecho (facultad que hasta antes de la publicación de esta ley, solo se tenía en el caso que se aplicaran las causales a) y b) del artículo recién mencionado, es decir falta de probidad, y conducta de acoso sexual), y además se establece que, si el trabajador hubiese invocado la causal del artículo $160 \mathrm{~N}^{\circ} 1$ letra f), falsamente o con el propósito de lesionar la honra de la persona demandada, y el tribunal hubiese declarado su demanda carente de motivo plausible, el trabajador estará obligado a indemnizar los perjuicios causados, y si la causal fue invocada maliciosamente, quedará sujeto a las otras acciones legales que procedan. Hasta antes de la publicación de esta Ley, las acciones antes referidas solo procedían en el caso que se invocara la causal de la letra b) del $\mathrm{N}^{\circ} 1$ del artículo 160 , es decir conductas de acoso sexual.

30 Senado, República de Chile, Boletín No 3.198-13. Disponible en: http://sil.senado.cl/cgibin/index eleg.pl?3198-13 [fecha de visita 25 de noviembre de 2011]. 
A fin de precisar los alcances del concepto de acoso laboral, específicamente en relación a qué tipo de conductas constituyen dicho fenómeno según nuestro legislador laboral, resulta interesante citar la interpretación que ha hecho la Dirección del Trabajo sobre el particular:

"Ahora bien, con el objeto de precisar el sentido y alcance del concepto de acoso laboral introducido por la ley en comento, resulta necesario, primeramente, desentrañar el significado de los términos "agresión" y "hostigamiento", "menoscabo", "maltrato" y "bumillación", utilizados por el legislador para determinar la verificación de las conductas asociadas a la acción que pretende sancionar.

Para ello cabe recurrir a las normas de interpretación previstas en el Código Civil, específicamente, aquella contenida en el primer párrafo del inciso $1^{\circ}$ de su artículo 20, según el cual, "Las palabras de la ley se entenderán en su sentido natural y obvio, según el uso general de las mismas palabras".

Al respecto, la reiterada y uniforme jurisprudencia de este Servicio ha sostenido que el sentido natural y obvio de las palabras es aquel que les otorga el Diccionario de la Lengua Española de la Real Academia Española, según el cual la expresión "agresión" es el "Acto de acometer a alguien para matarlo, herirlo o hacerle daño", definida también como "acto contrario al derecho de otra persona".

A su turno, la expresión "hostigamiento" es la "Acción y efecto de hostigar" y entre las acepciones de su infinitivo "hostigar", se cuentan las siguientes: "Molestar a alguien o burlarse de él insistentemente" e "Incitar con insistencia a alguien para que haga algo".

El mismo repertorio léxico define la palabra "menoscabo" como "efecto de menoscabar" $y$, a su vez, respecto de "menoscabar" contempla, entre otras acepciones "Causar mengua o descrédito en la honra o en la fama". A su turno, el concepto "maltrato" como "Acción y efecto de maltratar", en tanto que su infinitivo "maltratar" está definido como "tratar mal a alguien de palabra u obra" y también "Menoscabar, echar a perder".

Por último, la expresión humillación está definida por el citado diccionario como "Acción y efecto de humillar o humillarse y el infinitivo "bumillar", por su parte, como "herir el amor propio o la dignidad de alguien" $y$ "Dicho de una persona: pasar por una situación en la que su dignidad sufra algún menoscabo".

Conforme a lo expuesto en párrafos anteriores, es posible inferir que el legislador ha concebido las conductas constitutivas de acoso laboral en términos amplios, en forma tal que permita considerar como tales todas aquellas conductas que impliquen una agresión fisica hacia el o los trabajadores afectados o que sean contrarias al derecho que les asiste, asi como las molestias o burlas insistentes en su contra, además de la incitación a hacer algo, siempre que 
todas dichas conductas se ejerzan en forma reiterada, cualquiera sea el medio por el cual se someta a los afectados a tales agresiones u hostigamientos"31.

A pesar de que se trata de un buen intento por reconocer expresamente este conjunto de conductas como una práctica ilícita, y esencialmente contraria a la dignidad del ser humano, e incluir en su definición tanto al acoso vertical como el acoso horizontal, no resulta tan claro que la referida modificación pueda brindar soluciones a todas las problemáticas derivadas de este fenómeno:

- La definición de acoso laboral que consagra el artículo 2 del Código del Trabajo no es todo lo suficientemente explícita que se hubiera deseado, en el sentido de considerar como tal a las omisiones (solo se hace alusión a "agresiones u hostigamientos reiterados"), siendo que a través de ellas suele ser común que se consigan los objetivos del hostigador, principalmente tratándose del acoso vertical descendente (a través de omisiones como aislar al trabajador, no saludarle, no considerarlo como tal, y en definitiva, no otorgarle funciones que desempeñar).

- La exigencia de la reiteración en la comisión de las conductas constitutivas de acoso laboral, deja la interrogante de cuál es la periodicidad que se considerará suficiente para determinar la existencia del fenómeno. Ello no es menor, considerando, que desde las diferentes perspectivas analizadas en la presente investigación, fluye que uno de los elementos críticos a la hora de establecer criterios objetivos y seguridad y certeza jurídica en esta materia, es precisamente el lapso necesario para considerar que estamos en presencia del mobbing, entendido como un proceso.

- Se echa de menos la presencia de normas relativas a la prevención del acoso laboral, principalmente a través de establecer obligaciones para el empleador en este sentido, como sí ocurre en el derecho comparado. En este sentido, no basta el efecto disuasivo de introducir expresamente como una causal de caducidad del artículo $160 \mathrm{~N}^{\circ} 1$ a este tipo de conductas: es necesario un cambio de paradigma en relación al fenómeno en estudio, cambio dentro del cual el papel que corresponde al empleador es fundamental. Desde esta perspectiva, se podría haber considerado un rol más relevante por parte del empleador, en el fomento de la difusión de información acerca del acoso laboral como acto contrario a la dignidad de los trabajadores, o haber constituido en un contenido obligatorio del reglamento interno de

31 Dirección del Trabajo (2012). Ord.3519/034: Fija sentido y alcance de las modificaciones introducidas por la ley No20.607 al texto del inciso segundo del artículo $2^{\circ}$, del número 1 del artículo 160 y de los incisos segundo y sexto del artículo 171, todos del Código del Trabajo. Disponible en: http://www.dt.gob.cl/legislacion/1611/simple-article-101010.html [Fecha de visita 27 de diciembre de 2012]. 
la empresa, la prohibición expresa de las conductas constitutivas de acoso laboral.

- Ahora bien, en relación a la tutela jurisdiccional que la ley 20.607 ha querido instaurar en relación a las víctimas de acoso laboral, a través de la vía del despido indirecto, este punto nos merece dos comentarios.

Por una parte, y en base al análisis de la jurisprudencia realizado en el presente trabajo, nada debiera obstar a que el trabajador aún pueda seguir utilizando la acción y el procedimiento de tutela laboral para cautelar sus derechos, pudiendo ejercer la acción por despido indirecto conjunta o subsidiariamente con aquella, a la luz de lo dispuesto en el inciso final del artículo 489 del Código del Trabajo. Ello, porque uno de los principales efectos de las conductas de acoso laboral es producir en la víctima una vulneración de los más relevantes derechos fundamentales inespecíficos, como la honra, la dignidad, y la integridad psíquica.

En segundo lugar, la consagración legal de las conductas de acoso laboral como causal de despido indirecto, no soluciona todo el espectro en que es posible que se produzca el acoso laboral: del modo en que aparece consagrada la modificación legal, esta herramienta procesal solo sería aplicable al caso del acoso vertical descendente (es decir, cuando el empleador o su representante sean los acosadores y uno o más trabajadores, las víctimas). A mayor abundamiento, con la nueva normativa sigue sin solución uno de los problemas propios del despido indirecto, como es que este implica necesariamente poner fin al vínculo laboral con el empleador, obligando al trabajador a perder su puesto de trabajo si desea obtener que se sancione a aquel por las mencionadas conductas ${ }^{32}$. Esta problemática ya se venía suscitando antes de la entrada en vigencia de la ley 20.607, al utilizarse el despido indirecto en casos en que el acosador laboral fuese el empleador, por la vía de interpretar que las conductas de acoso laboral configuran la causal del artículo $160 \mathrm{~N}^{\circ} 7$, en relación al deber general de protección y cuidado del artículo 184 del código laboral, y al deber de respeto, propios del contenido ético-jurídico del contrato de trabajo.

Frente a esto último, el procedimiento de tutela laboral aparece mucho mejor posicionado, pues permite abordar esta problemática durante la ejecución misma del contrato de trabajo, sin necesidad de forzar la terminación del vínculo laboral, pero asegurando al trabajador una adecuada reparación, como asimismo imponiendo las sanciones a que haya lugar en contra del empleador acosador (como ha quedado de manifiesto en el citado caso de la trabajadora musulmana, Nora Melo). Adicional-

32 López, Diego (2007). "Marco jurídico del acoso laboral en Chile". Reporte para el Proyecto "Research, policy and practice with regard to work-related mental health problems in Chile: a gender perspective". Disponible en: http://www.acoso-laboral.cl/MarcoJuridiAcosoLaboral. pdf [fecha de visita 30 de diciembre de 2012], p.9. 
mente, en el procedimiento por despido indirecto, se deja al trabajador en una compleja posición, al tener que demostrar que, efectivamente, las conductas del empleador son constitutivas de acoso laboral (máxime si con la modificación legal en estudio, este procedimiento se deberá abocar a los elementos expresamente señalados en el inciso $2^{\circ}$ del artículo 2 del Código del Trabajo), lo que conlleva la dificultad probatoria que implica el que las conductas constitutivas de acoso laboral no suelen evidenciar la real intención perjudicial del hostigamiento. Por contrapartida, como se ha visto, en el procedimiento de tutela laboral esta situación se compensa a través de la herramienta de la prueba indiciaria, por lo que resulta mucho más adecuado a la satisfacción de una tutela judicial efectiva para la víctima del mobbing.

Sin perjuicio de las observaciones anteriores, quizás el mayor mérito de la modificación introducida por la ley 20.607 , lo constituya el hecho de que entrega un concepto de acoso laboral, estableciendo elementos que puedan orientar a los jueces al momento de tener por configurada esta práctica, lo que sin duda, es un avance indiscutible.

\section{4) CONCLUSIÓN}

El acoso moral laboral es un fenómeno complejo, por su propia naturaleza, lo que implica necesariamente que sea campo de estudio de diversas disciplinas. Ello no es algo menor, sobre todo para nuestra realidad nacional, en donde han sido nuestros tribunales los que han debido llenar el vacío legal existente en cuanto a su conceptualización. En general, podemos decir que se trata de un conjunto de conductas hostiles, activas u omisivas, que constituyen un proceso sostenido en el tiempo, en donde los sujetos involucrados deben estar vinculados por una relación laboral, pudiendo producirse el acoso desde el empleador a sus trabajadores, o entre compañeros de trabajo, teniendo como finalidad común el aislar y degradar a la víctima dentro de su ambiente laboral, y siendo su resultado el deterioro progresivo de la salud, las condiciones de trabajo, e incluso en la calidad de vida de la víctima.

Entre las principales ventajas que el procedimiento de tutela laboral presenta en relación con el control y sanción del mobbing, destacan su diseño específicamente orientado hacia la protección de los derechos fundamentales, lo que se traduce en elementos innovadores, como el sistema de prueba de indicios, que claramente representa un factor muchas veces decisivo al momento de determinar la existencia de las vulneraciones producidas por el acoso. Asimismo, destaca la obligación del juez de incluir en la sentencia que resuelva la tutela, la sanción, las medidas que impidan la reiteración de los actos lesivos, la restitución de las víctimas al estado 
anterior a la vulneración, e incluso ha permitido proyectar la prevención de cara a futuras vulneraciones de derechos fundamentales.

La necesidad de una legislación específica que se haga cargo del acoso laboral es un tema que debe seguir debatiéndose cuidadosamente: el análisis jurisprudencial llevado a cabo en la presente investigación ha dejado en evidencia que el procedimiento de tutela laboral, como se encuentra diseñado actualmente, contiene las herramientas necesarias para acoger plenamente la tutela inhibitoria, restitutoria y resarcitoria de las víctimas de acoso, incluso sin necesidad de hacer referencias a un concepto de mobbing, sino que centrándose directamente en constatar la lesión de derechos fundamentales, en donde el acoso laboral constituye el medio a través del cual esta se materializa. Claramente, mucho tiene que ver en ello la actitud del juez de la causa, en aplicar dicho procedimiento tomando en consideración las especiales características que el mobbing imprime al modo como se produce la vulneración. No se debe desatender el riesgo implícito en plasmar definiciones en la ley, de un fenómeno con tantas aristas como el mobbing: el definir siempre implica establecer límites, lo que no es algo propiamente negativo: de hecho, la modificación introducida por la ley 20.607 se erige en una positiva evolución en la senda de obtener mayor certeza jurídica. Sin embargo, ello no debe tener como consecuencia el reducir la protección de las víctimas de acoso, excluyendo situaciones que claramente debieran ser dignas de sanción: lo contrario implicaría restringir las aspiraciones de justicia de las víctimas de acoso laboral a una tutela judicial efectiva solo en lo meramente formal.

Establecer los elementos configurativos comunes a todas las situaciones que potencialmente puedan constituir acoso laboral, en nuestro parecer, resulta adecuado a la consecución de los valores tenidos en vista para resolver el problema de la presente investigación: por una parte, entrega bases uniformes a los jueces para calificar las conductas, lo que redunda en mayor seguridad jurídica, además de propiciar el enriquecimiento en la fundamentación de las sentencias, y por otra, ninguna denuncia o demanda por acoso laboral deberá correr el riesgo de ser excluida a priori, simplemente por no coincidir con una particular noción de mobbing, que dependiera del respectivo sentenciador.

\section{5) BIBLIOGRAFÍA}

- Álvaro de Oliveira, Carlos Alberto (2009). "El derecho a la tutela jurisdiccional efectiva desde la perspectiva de los derechos fundamentales". Revista de Derecho (Valdivia), Vol. XXII, N ${ }^{\circ}$, pp.185-201.

- Arastey Sahun, María Lourdes (Coordinadora) y Gimeno Lahoz, Ramón (Relator) (2006). Conclusiones del Seminario: Los límites del 
Mobbing. Su deslinde de figuras afines. Disponible en: http://www. sociedadvascadevictimologia.org/adjuntos/Mobbing.pdf [fecha de visita 2 de agosto de 2011].

- Dirección del Trabajo (2012). Ord.3519/034: Fija sentido y alcance de las modificaciones introducidas por la ley No20.607 al texto del inciso segundo del artículo $2^{\circ}$, del número 1 del artículo 160 y de los incisos segundo y sexto del artículo 171, todos del Código del Trabajo. Disponible en: http://www.dt.gob.cl/ legislacion/1611/simple-article-101010.html [fecha de visita 27 de diciembre de 2012].

- Gamonal Contreras, Sergio (2008) El procedimiento de tutela de derechos laborales. Santiago de Chile: Editorial LegalPublishing Chile.

- Gamonal Contreras, Sergio y Prado López, Pamela (2006) El Mobbing o Acoso Moral Laboral. Santiago de Chile: Editorial LexisNexis.

- Gimeno Lahoz, Ramón (2004) La Presión Laboral Tendenciosa (Mobbing). Tesis doctoral. Girona: Universitat de Girona. 535 pp. Disponible en: http://www.opas.org.br/gentequefazsaude/bvsde/ bvsacd/cd49/presion.pdf [fecha de visita 30 de junio de 2011].

- Jefferson Cerda, Marcela (2004) El Acoso Psicológico en el Trabajo. Su trato y reconocimiento en el Derecho Chileno. Tesis para optar al grado de Licenciado en Ciencias Jurídicas. Temuco: Universidad Católica de Temuco. 55 pp. Disponible en: http://biblioteca.uct.cl/ tesis/marcela-jefferson/tesis.pdf [fecha de visita 22 de julio de 2011].

- López, Diego (2007). "Marco jurídico del acoso laboral en Chile". Reporte para el Proyecto "Research, policy and practice with regard to work-related mental health problems in Chile: a gender perspective". Disponible en: http://www.acoso-laboral.cl/ MarcoJuridiAcosoLaboral.pdf [fecha de visita 30 de junio de 2011].

- López Cabarcos, M.Angeles; Vásquez Rodríguez, Paula (2003) La ley al servicio de la víctima de Mobbing. Disponible en: http://www. ucm.es/cont/descargas/documento33089.pdf [fecha de visita $22 \mathrm{de}$ julio de 2011].

- Medeiros de Oliveira, Flavia (2005) El Acoso Laboral. Tesis doctoral. Valencia: Universitat de Valencia. 720 pp. Disponible en: http://tdx. cat/bitstream/handle/10803/9674/flavia.pdf?sequence $=1$ [fecha de visita 22 de julio de 2011].

- Palavecino Cáceres, Claudio (2004). "La protección contra el Acoso Psíquico Laboral en el ordenamiento jurídico chileno". Revista de Derecho (Valdivia), Vol. XVII, pp. 6389. Disponible en: http://www.scielo.cl/scielo.php?pid=S0718$09502004000200003 \&$ script $=$ sci $\quad$ arttext\&tlng=es [fecha de visita 22 de julio de 2011]. 
- Senado, República de Chile, BOlETín No 3.198-13. Disponible en: http://sil.senado.cl/cgi-bin/index eleg.pl?3198-13 [Fecha de visita: 25 de noviembre de 2011].

- Silva Irarrázaval, Luis Alejandro (2011). "Supremacía constitucional y tutela laboral". Revista de Derecho (Valdivia), Vol. XXIV, $\mathrm{N}^{\circ} 1$, pp. 31-48.

- Torres Mesías, César; Otazo Carrasco, Óscar (2005) Acoso Psicológico Laboral: Inédita Memoria para optar al grado de Licenciado en Ciencias Jurídicas y Sociales. Santiago de Chile: Universidad de Chile. 583 pp. Disponible en: www.cybertesis.uchile. cl/tesis/uchile/2005/de-torres c/pdfAmont/de-torres c.pdf [fecha de visita 22 de julio de 2011].

- Ugarte Cataldo, José Luis (2007). "La tutela de derechos fundamentales y el derecho del trabajo: de erizo a zorro". Revista de Derecho (Valdivia), Vol. XX, N², pp. 49-67.

- Ugarte Cataldo, José Luis (2009). "Tutela laboral de derechos fundamentales y carga de la prueba". Revista de Derecho de la Pontificia Universidad Católica de Valparaiso, Vol. XXXIII, pp. 215228. Disponible en: http://www.scielo.cl/pdf/rdpucv/n33/a05.pdf [fecha de visita 15 de abril de 2011].

- Ugarte Cataldo, José Luis (2011). "Derechos humanos en la relación de trabajo: el caso del acoso laboral”. En: Contesse Singh, Jorge (Director y Editor General): Informe anual sobre derechos humanos en Chile 2011. Santiago de Chile: Ediciones Universidad Diego Portales, pp. 265-283. Disponible en: http://www. derechoshumanos.udp.cl/informe-anual-sobre-derechos-humanosen-chile-2011/ [fecha de visita 15 de noviembre de 2011].

\section{JURISPRUDENCIA:}

- Corte de Apelaciones de Iquique. 4 de octubre de 2010. Rol No 73-10. "Pérez Devia, Duxann P. c/ Serviclínica Iquique S.A." Disponible en: http://cl.microjuris.com/ getContent? reference $=\mathrm{MJCH}$ MJJ25055\&links=[MOBBING] [fecha de visita 8 de agosto de 2011].

- Juzgado de letras del Trabajo de Antofagasta. 18 de enero de 2010. RIT T-13-2009. "Morales Iriondo, Pedro c/ Productos Fernández”. Disponible en: http://sentenciasreformalaboral.blogspot. com/2010/02/tutela-sjl-antofagasta-18012010-rechaza.html [fecha de visita 08 de agosto de 2011].

- Juzgado de Letras del Trabajo de Iquique. 27 de agosto de 2010. RIT T-20-2010. "Pérez Devia, Duxann P. c/ Serviclínica Iquique S.A.” Disponible en: http://sentenciasreformalaboral. 
blogspot.com/2010/10/tutela-jlt-iquique-26082010-acoge.html [fecha de visita 3 de diciembre de 2011].

- Juzgado de Letras de Puente Alto. 10 de marzo de 2010. RIT T-1-2009. "Astorga Guajardo, Amada B. c/Corporación Municipal de San José de Maipo". Disponible en: http:// sentenciasreformalaboral.blogspot.com/2010/07/tutela-jlt-puentealto-10032010-acoge.html [fecha de visita 8 de agosto de 2011].

- Primer Juzgado de Letras del Trabajo de Santiago. 26 de abril de 2010. RIT T-38-2010. "Inspección Provincial del Trabajo de Santiago c/TP Chile S.A.”. Disponible en: http:// sentenciasreformalaboral.blogspot.com/2010/04/tutela-jlt-1rosantiago-26042010-acoge.html [fecha de visita 1 de diciembre de 2011].

- Segundo Juzgado de Letras del Trabajo de Santiago. 12 de febrero de 2010. RIT T-63-2009. "Inspección Provincial del Trabajo de Santiago c/CENCOSUD Retail S.A.". Disponible en: http:// sentenciasreformalaboral.blogspot.com/2010/02/tutela-2do-jlt12022010-acoge-tutela.html [fecha de visita 8 de agosto de 2011].

- Segundo Juzgado de Letras del Trabajo de Santiago. 14 de enero de 2011. RIT T-306-2010. "Medina Burgos, Ximena Noemí c/Universidad Tecnológica de Chile INACAP". Disponible en: http://blog.bligoo.cl/content/view/1286669/SENTENCIA-DEACOSO-MORAL-O-MOBBING-enero-2011.html [fecha de visita 4 de noviembre de 2011]. 